\title{
Costumes in Igogo Masquerade Theatre of the Ekiti People
}

\section{*Lilian Eguriase BAKARE}

\begin{abstract}
This article analyses costume materials and designs as well as signs, symbols and their meanings in the masquerade theatre of the Igogo community in Ekiti State, Nigeria. This became necessary because of the need to make this indigenous art of the people relevant to their contemporary existence and realities by bridging the knowledge gap and invalidate the error of perception which causes a neglecting of this noble heritage and sellable entertainment commodity by the younger generations of Igogo people, especially the formally educated elite. Deploying the key informant interview (KII), semiotic analysis and direct observation methods, the study highlights and discusses the socio-aesthetic attributes of Igogo masquerade theatre, with particular reference to the costumes and their socio-historical as well as entertainment and tourism potentiality.
\end{abstract}

Keywords: Costumes, Igogo masquerade theatre, Ekiti people, Semiotic analysis, Nigeria

\section{Introduction}

Igogo community has a robust masquerade theatre tradition that is proudly indigenous to the people. This art should naturally be part of this communityôs offering to the modern/contemporary tourism and entertainment market as commodity for promotion and commerce both nationally and internationally. But, the case is different. This cultural phenomenon is rather perceived by those

*Lilian Eguriase BAKARE of the Department of Theatre and Media Arts Federal University, Oye-Ekiti Email: nifekare@gmail.com 
who should market it, as a backward expression of idol worshipping; an activity that should be extinguished for its nonconformity to the dictates of the Abrahamic religions (Fieldwork, 2014). This observation inspired this study, which is to analyse the aesthetics and semiotics of the masquerade samples in this community with the intention to highlight their socio-historical as well as entertainment and tourism values which make them relevant to the continual survival of the people in contemporary times. This shall be done through a discussion of the garments and the oral narratives that caused the existence of each masquerade.

It important to note, however, that several other studies have been carried out on masquerades, their costumes (costume materials) and socio-aesthetic imports among different peoples in different parts of Nigeria. Ododo, Braimah and Sunnie-Ododo (2012) examined the use of costumes and make-up in Menwara festival of the Kanakuru people of Shani chiefdom in Bornu State of Nigeria by analysing their roles and the levels of changes that have occurred overtime. Okoye (1999) looked at masquerade performances, which subsume dance, music, costume and other visual and aural arts, as popular forms of communal cultural expression among the Igbo people of south-east Nigeria. As well, Omoera and Oseghale (2012) claim that the Esan people of southsouth Nigeria consider masquerade art $і ̈$ Igbabonelimhin (clapping for the ancestors) as a performative revue of communing with deified masquerades. While the healing potential of theatre constituted the crux of Rasheed Musaôs examination of the Ehoro Iba masquerade festival of Agbeyeland (2001), Agberia (2003) focuses on the socio-aesthetic values, boisterousness and colourful costumes of Adane Okpe masquerade festival of the Okpe people.

Regardless of the clime or culture, the physical appearance of a masquerade is a great determinant of its perception, attraction and, therefore, acceptability or otherwise. It is in this context that this article focuses on Igogo masquerade costumes with an argument for their technological reproduction if the masquerade theatre must be mainstreamed into the contemporary global entertainment and tourism market. Igogo is a town in Ekiti State, Nigeria. It is one of the Ekiti towns which border Kwara State in 
the northern region of Ekiti State. Igogo is a fairly large community which is continually being depleted by the daily migration of its formally educated indigenes to the cities. The bulk of those living in the community are farmers, petty traders and local herbal doctors. This is the group that has continued with the practice of the traditional masquerade theatre of the community (Bakare, 2017). The sample masquerades under discussion here are: Afisoke, Ajamolaya, Iyekiye and Eegun Elewe. Each of them shall be discussed here.

\section{Afisoke Masquerade of Igogo Ekiti}

The Afisoke masquerade was instituted for the continual remembrance of a great mythical war General, Afisoke, who was the Generalissimo of Igogoôs ancient army. He was reputed to have won every battle for his people and always succeeded in warding off all external aggressions. After his death, a masquerade was instituted in his honour and remembrance. This masquerade called Afisoke is today the leader of all Igogo masquerades. According to information gathered from the field, Afisoke is the head of the pantheon of masquerades in Igogo Ekiti (Fieldwork, 2014). Afisoke is a war masquerade. It is believed to have mystical powers with which to rescue the people from war situations. This is why it is always accompanied by this chant:

Yoruba: Ke ma jogun ijulu eee X3

Afisoke legiri

Ke ma jogun ijulu ooo

Meaning: He wards wars off the land X3

Afisoke the powerful, he wards wars off the land.

In the absence of wars in contemporary times, the Afisoke masquerade is displayed once in three years. Each time Afisoke is displayed, he moves about praying for the people and the land. The Afisoke masquerade of Igogo-Ekiti has a physical aesthetic appearance that quickly suggests to its audience a simple but technically accurate combination of colours into complementary splits. Although the masquerade custodians might have been unconscious of any trace of formal techniques in their application 
of colour, the large mass of red requires the presence of a smaller amount of green to generate the complementary combination accepted as valid by professional master-painters all over the world.

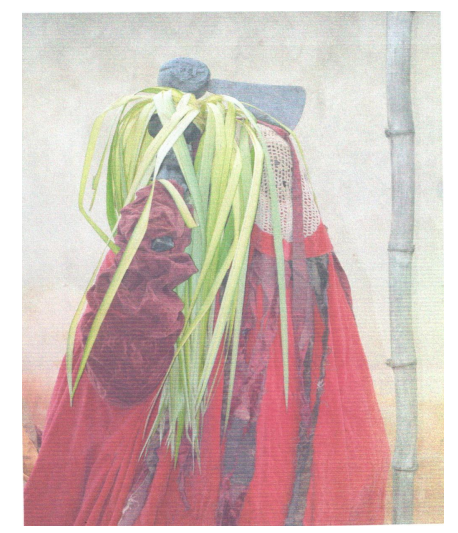

Plate 1: Afisoke masquerade. Note the axe held to the head. The palm fronds are tied to the wooden handle of the axe (Source: Fieldwork, 2014).

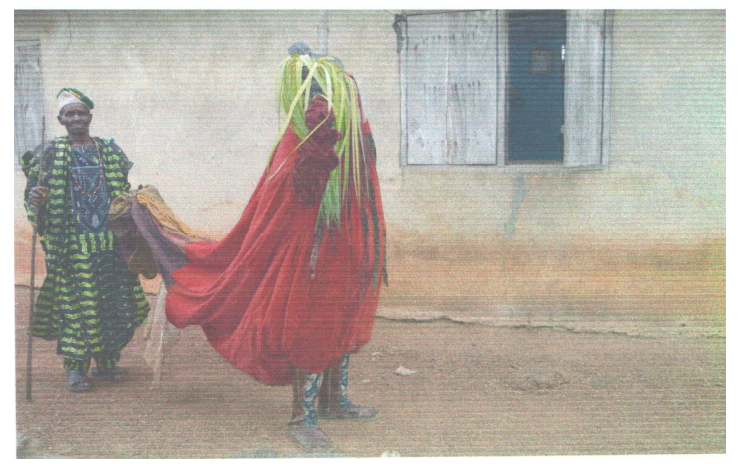

Plate 2: Afisoke masquerade in performance. Note theoverflow of the costume being held by his acolyte (Source: Fieldwork, 2014).

In the same vein, a little amount of yellow is often required on a pallet that carries some substantial amount of purple. While 
one may consider that the amount of purple being almost equal to the amount of yellow can also generate a discordant effect, the greenish temperament of the yellow dismisses any referral of proficiency in this particular masquerade costume. The masqueradeôs hands are not quite visible because they are probably covered up in the surplus costumes giving the masquerade a single magnitude. However, the anatomical forms suggest that the left hand is at the hip while the other hand bears an axe across the right shoulder to the head of the masquerade.

One could notice that different materials are involved in the design while the dominant material is a large piece of cotton in plain red colour, the head of the masquerade is designed in pale cream or off-white colour with a net-like material for sight. The net on the face and some long straps made in leather-like fabrics extending to the knees of the masquerade appear sufficient to break the dull expanse of red on the dominant background costume. The footwear of the Afisoke masquerade is a combination of leather and woven fabric hues serving as a transition from the leather straps from the face of the masquerade to its feet as required by the ñunityò as a principle of design. We are informed that the current costume of Afisoke has existed for over a hundred years (Fieldwork, 2014).

\section{Ajamolaya Masquerade of Igogo Ekiti}

The word Ajamolaya means ñintimidatorò or ñterroristò This masquerade was established to frighten or scare the crowd away from obstructing the performances of masquerades during masquerade festivals. As the masquerades perform at the centre of the arena, Ajamolaya goes round the circle frequently to guard against the incursion of the ever surging crowd into the arena so that every member of the audience can see the performance clearly from afar.

Thus, Ajamolaya masquerade is the coordinator of the activities of men and masquerades during the masquerade festivals. $\mathrm{He}$ is like the provost marshal instilling discipline into everyone present. He uses a walking stick to control the crowd. Ajamolaya is highly feared by the people because of the belief that the nearer somebody is to the cowries ring on his face, the more the person is 
susceptible to the effects of the masqueradeôs curses. So, people naturally run away as he approaches. We are informed by the Priest of Ajamolaya that the cowries ring is over two hundred years old.

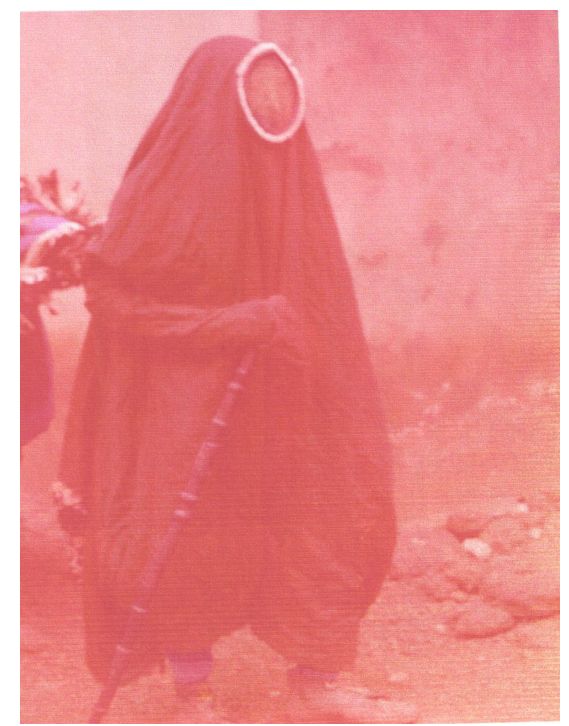

Plate 3: Full view of Ajamolaya masquerade holding the long, pointed stick with which he harasses the audience (Source: Fieldwork, 2014).

\section{Aesthetics}

The Ajamolaya masquerade is clad in a simple completely red baggy costume made of red cotton and sewn in a manner that hides the identity of the bearer completely. On the only visible hand of the masquerade is a staff ornamented with intricate carving of traditional patterns. There is a ring of cowrie shells round the boarders of the face of the masquerade. Also there is a netted proportion of the face sufficient to make the masquerade see.

\section{Iyekiye Masquerade of Igogo Ekiti}

Igogo is a land of itinerant magical performers. The Iyekiye masquerade is the masquerade representative of this robust tradition. Iyekiye masquerade is an embodiment of cultural 
magical performance. $\mathrm{He}$ is a displayer of performative magic. Sometimes, the masquerade dances and suddenly the performer inside the costume disappear, living the mask and the costume lying empty and flat on the ground. Then after some minutes, the costume begins to move to music until it is fully re-inhabited by the performer and the masquerade is back on his feet dancing. Also, the Iyekiye masquerade, while performing, intermittently throws the axe he holds into the air and catches it with his mouth. He executes different magical acts when performing as an icon of the peopleôs itinerant magical display tradition.

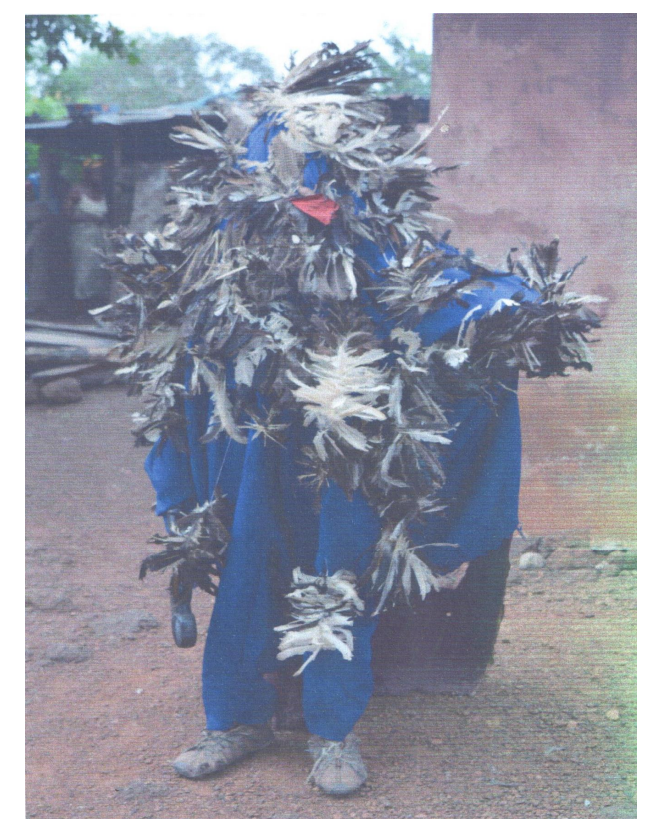

Plate 4: Iyekiye masquerade. Note that feathers used to cover the entire inner clothing. Many of the feathers have dropped off because of long years of usage (Source: Fieldwork, 2014).

\section{Aesthetics}

The Iyekiye masquerade is a combination of feathers and cotton materials. There is blue on the background clothing with which a 
massive covering is made for the masqueradeôs entire body. Attached to the blue material are feathers of different types of birds. The assorted combination of feathers, from which the masquerade got its name, generates a traditional pallet of mainly black, white and greys with no particular reference to any known formal application of colour. However, save the presence of white, the application of black feathers on a deep blue piece of cloth would suggest deep feeling. The presence of white feathers sends substantial sparkles to the eyes of the audience intermittently breaking any suggested emotion.

The major aesthetic importance of this masquerade is in the plethora of feathers which when viewed in company of other masquerades with organised designs and smooth ornamentation cause deliberate disorganisation in order to create optical variation. This avant-garde approach has been used by masters over the years. To distract the eyes from the boredom of watching similar elements for too long, they bring disorder into the picture to create activity. This study reveals that the technique might have had a connection with traditional masquerading.

\section{Eegun Elewe of Igogo Ekiti}

Eegun Elewe is a masquerade instituted for dance entertainment. The expression ñEegun Eleweò means ñthe masquerade that owns Eweò ñEweò means rattles. These rattles which are fastened to the legs of the masquerade generate melodious sound as the masquerade dances to bata music. The main duty of Eegun Elewe is to dance round the village and entertain the people. As he goes round performing he also uses the chant medium to pray for people and praise important persons. The Eegun Elewe is virtuous dancer who has mastered the language and idioms of bata and dundun music. 


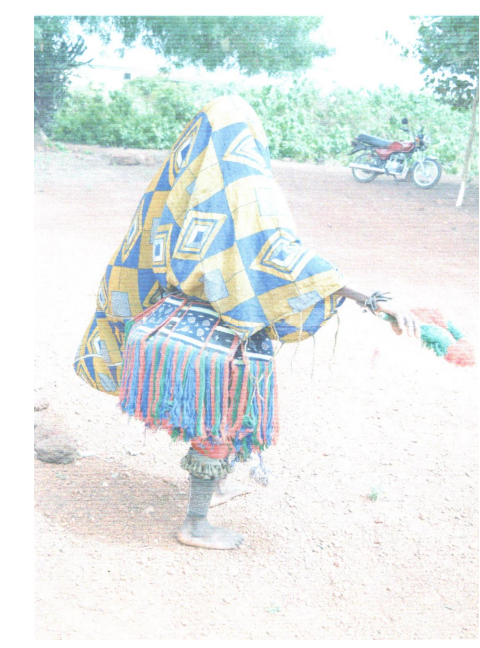

Plate 5:

The back view of Eegun Elewe (Source: Fieldwork, 2014), NOTE THE SKIRT WHICH IS IN LAYERS OF WOOL BELTS

\section{Aesthetics}

Eegun Elewe is a physically complex masquerade because of the nature of its costumes. The masquerade, which is divided into three broad parts, carries diverse accessorial aesthetics. The first part is from the head of the masquerade to its waist covered in multicoloured clothing background. The fabric is twisted in a fashion that tilts completely on the left arm, covering the entire loins, torso and head of the masquerade, saving only the right arm with which the masquerade carries additional costume accessories and theatrical props such as hand fans and horsetail.

The second part is the combination of leather and wool woven and embroidered like flat garlands arranged in a manner that allows them to skirt around the masquerade as he dances. Probably suggested by the performative necessity of this masquerade, the bulging circumference of the masqueradeôs skirt suggests a skeletal girdle underlying it. The third part is an arrangement of the ñeweò (metal conical rattleboxes) of about 
thirty in number, around the two legs of the masquerade. Each stringed set containing brass rattleboxes of about an adult toe each is tied to the legs of the Eegun Elewe as part of the musical accompaniment to the performance of the masquerade.

\section{Semiotic Analyses of the Masquerade Costumes}

\section{Afisoke}

The predominant deep red colour signifies strength, power and fearsomeness all of which are socio-aesthetic attributes of the dreaded warrior which the masquerade represents. The right hand, the only hand of the masquerade which is seen, perpetually holds a battle axe to the head of the masquerade. This communicates the fact that the masquerade carries the peopleôs battles on his head. The masquerade is telling the people: ñyour battles, I carry on my headò. The palm fronds fastened to the battle axe signifies the spiritual status of the battle axe. The brown long strands of leather that are fastened to the battle axe $\ddot{I}$ like fabrics which runs from the head to the knees of the masquerade, depict the long dreadlocks of the warrior i Afisoke, who was said to be a Dada, a human born with natural dreadlock. The dreadlocks are believed to be the source of his power.

\footnotetext{
Ajamolaya

The dominant red colour is a symbol of fear, terror and power. The cowries ring on the face heightens the fear that Ajamolaya creates in peopleôs minds. But, more importantly, the cowries ring symbolises the ámmortabilityô and ántouchabilityô of the Ajamolaya masquerade. Ajamolaya, being the provost marshal or chief whip who maintains discipline and order during festivals needed to be insulated against reprisal or retaliatory attacks. The impression was therefore created in the consciousness of the society that Ajamolaya is indestructible, immortal and therefore untouchable. The unbroken ring of white cowrie shells on the face is a symbol of these attributes. The ornamented staff usually held by Ajamolaya symbolises authority and power to control people.
} 
Iyekiye

The name Iyekiye means ñassorted feathersò. The masquerade, therefore, derives his name from the multitude of feathers that are attached to the clothing background of his costume. The design of Iyekiye costume derives from the bird, not a particular bird but all birds and that is why different manners of feathers are found on the costume. A clothing attachment at the back also represents the tail of a bird. The bird motif is informed by two things: first is the fact that the bird is the Yoruba symbol for witches and witchcraft. Iyekiye is believed to be a witch because of its magical prowess. As earlier stated, Iyekiye masquerade is a representation of the robust magical prowess the Igogo people are known for. This prowess is attributed to the power of witchcraft, and in Ekiti, the bird is the symbol of witchcraft. This explains why Iyekiye masquerade is conceived as a bird with a multitude of assorted feathers that signify magical prowess and witchcraft (Abimbola, 1970). Second are Iyekiyeôs acclaimed disappearing acts. During performances, Iyekiye disappears and appears at will. This is consistent with the character of the birds that fly to and fro at will.

\section{Eegun Elewe}

Eegun Elewe is also called Eegun Alare which means ñthe playing masqueradeò The play here means dance. This masquerade is exclusively for trained dancers. The art of dancing is a highly revered art form in Igogo society. Dancing, combined with acrobatics, is considered by Igogo people to be the king of all art forms. Therefore, talented dancers and acrobats are held in high esteem and treated with awe. In the Igogo pantheon of masquerades, this group of people are represented by Eegun Elewe masquerade. This is why the entire costume is a replica of a typical dance costume.

The clothing material which covers the masquerade from head to the waist including the left hand is to enhance dance movements. The bare left hand holds the traditional hand fan or the horsetail, the props that are synonymous with professional dancing in Yoruba land. The skirt-like swirling leather and wool around the waist is also there to emphasise the waist dance 
movements. The name Eegun Elewe means ñthe masquerade that has eweò. ñEweò is the traditional rattle, cast in alloy metal, which is fastened around the ankles of traditional dancers in this community. These rattles are also conspicuous on the ankles of the Eegun Elewe masquerade. This signifies Eegun Elewe as an itinerant virtuoso dancer.

\section{The Limitations of Masquerade Costumes in Igogo Zone}

In Ekiti State, Igogo is one of the most technologically advanced in the choice of costume materials. For instance, instead of using perishables such as palm fronds and carved woods like most other towns do, they use clothing materials, metallic rattles, beads and cowries, seasoned leather from animal skin and feathers. However, in spite of this seeming advancement in comparison to the other towns, the materials used in Igogo still have their own major limitations.

\section{Clothing Materials}

The clothing materials become worn out after some years of usage because it is believed that for reasons of efficacy, new masquerade costumes are not built for every season. Therefore, a particular costume becomes faded and rag-like after some years of usage. Also, the use of clothing materials can cause health hazards for the wearer because of the choice of materials and fabrics used. Usually, materials of different colours are used, stringed with different types of ornaments, and after rigorous masquerade performances, these costumes are kept in storage without any form of preservation, washing or any form of treatment because, it is a taboo to do so. This makes the clothing materials to deteriorate fast making the masquerades to appear dirty, scruffy and unattractive.

\section{Beads and Cowries}

The type of beads used makes the costumes very heavy, too heavy for the masked performer to be as active as he ought to. They inhibit the supposedly rigorous movements of the masked performer or masquerader. The cowrie, apart from being heavier 
than the beads, is one of those materials that have invested the Ekiti masquerade with the ritualistic status and, therefore, make it unacceptable to the modern audience. In Ekiti, the appearance of the cowry on anything conjures magical, sacred and occult feelings. Its continuous use as accessory will make the masquerade art a hard sell in contemporary times.

\section{Feathers}

These are epidermal growths that form the distinctive outer covering or plumage of birds. When feathers appear on masquerade costumes, they look aesthetically pleasing; however, because it is the natural birdsô feathers that are used, it is a perishable material. It is only safe to use once, and that is when it is still fresh. When kept for another masquerade season, they would have become worn out and smelly by the effects of attacks from insects and other parasites.

\section{Leather}

Seasoned leathers sourced from animal skins are also used as materials. Even though they are durable because of the seasoning, however, they still do not have the finishing and the aesthetics of synthetic leather.

\section{Conclusion}

It is expected that the information provided in this study on the socio-historical significance of Igogo masquerades will diminish the disdain borne by the elite Igogo indigenes towards their indigenous masquerade theatre. It is further expected that new technological possibilities such as polymer will be introduced to the making of the masquerade costumes. The adoption of polymer materials will eliminate the ritual features and reduce the masquerades to art works, thereby making them more attractive and acceptable to the contemporary entertainment seekers. This will reduce the limitations of the existing costumes, in so doing, increasing the marketability of Igogo masquerade theatre in the contemporary tourism and entertainment circuits. 


\section{References}

Abimbola, W. (1970). The origin of the Yoruba masque theatre: The use of Ifa divination corpus as historical evidence. African Notes.

Agberia, J.T. (2003). The Adane Okpe masquerade festival of Okpe people. In G.G. Darah et al. (eds.). Studies in arts, religion and culture among the Urhobo and Isoko people. Port Harcourt: Pam Unique Publishing.

Bakare, L.E. (2017). Construct and prospect of mass reproduction of costumes in Ekiti masquerade theatre. Unpublished doctoral dissertation, University of Abuja, Abuja.

Musa, R. (2001).The theatre of healing: Ehoro Iba masquerade festival of Agbeyeland as paradigm. The Abuja Communicator, 1 (1), 111-112.

Ododo, S.E., Braimah, B.A. and Sunnie-Ododo, M.O. (2012). Costume and make-up in Menwara festival performance of the Kanakuru. In H.O. Ekwuazi, C.O. Aluede and O.S. Omoera (eds.). The Anthropologist special volume 9 Contemporary discourses on media and theatre arts studies in Nigeria (121-126). Delhi: Kamla-Raj Enterprises.

Okoye, C. (1999). Form and process in Igbo masquerade art. Unpublished doctoral dissertation, University of Ibadan, Ibadan.

Omoera, O.S. and Oseghale, F. (2012). An emic exploration of the Igbabonelimhin dance-theatre of the Esan of Edo State, Nigeria. In H.O. Ekwuazi, C.O. Aluede and O.S. Omoera (eds.). The Anthropologist special volume 9 Contemporary discourses on media and theatre arts studies in Nigeria (105-111). Delhi: Kamla-Raj Enterprises.

\section{Fieldwork Sources/Key Informant Interviews}

Interview with Mr. Kokoirin Ayinde, head of griots in Igogo Ekiti. August, 2014.

Interview with Chief Oloko Idemo, the head of the masquerade cult in Idemo Street, Igogo. August, 2014. 
Interview with Chief Olaoye Obaro, the head and chief administrator of the masquerade traditions of Igogo kingdom. August, 2014.

Interview with Oloko Ilegosi, the head of the masquerade cult in Ilegosi Street, Igogo. September, 2014.

Interview with Chief Afuye Omonikan, the Odofin of Igogo Ekiti. September, 2014. 